\title{
FRICTIONAL POWER LOSSES ON SPUR GEARS WITH TIP RELIEFS. THE FRICTION COEFFICIENT ROLE
}

\author{
A. Diez-Ibarbia, A. Fernandez-del-Rincon, A. de-Juan, \\ M. Iglesias, P. Garcia, F. Viadero \\ Department of Structural and Mechanical Engineering, University of Cantabria. Avda. \\ de los Castros s/n 39005 Santander, Spain.
}

\begin{abstract}
In this proposal, the effect of the friction coefficient on the efficiency of spur gears with tip reliefs was analysed. For this purpose, the efficiency values using an average friction coefficient along the mesh cycle were compared with those obtained implementing an enhanced friction coefficient formulation, which is based on elastohydrodynamic lubrication fundamentals. In this manner, it can be established the differences between both formulations in the efficiency and friction coefficient values, as well as the advantages of using this enhanced friction coefficient with respect to formulations implemented in traditional approaches of efficiency calculation. In addition to studying the impact of the friction coefficient choice on efficiency, the profile modifications influence on the friction coefficient and efficiency was also assessed. In this regard, three tip relief case studies were set out; pinion tip reliefs, driven wheel tip reliefs and profile modifications in both gears. From the results, it was inferred that the choice of friction coefficient formulation clearly influences the efficiency in gear transmissions with tip reliefs, obtaining discrepancies between both formulations with regard to which tip relief case study provides the lowest efficiency values.
\end{abstract}

Keywords: Efficiency, Friction Coefficient, Power losses, Load sharing, Tip relief

\section{Nomenclature}

$D C R$ Double-contact region

Preprint submitted to Mechanism and Machine Theory

September 20, 2017

(C) 2017 This manuscript version is made available under the CC-BY-NC-ND 4.0 license http:// creativecommons.org/licenses/by-nc-nd/4.0/ 
EHL Elastohydrodynamic Lubrication

$F C$ Friction Coefficient $(\mu)$

$F D C R$ First double-contact region

$F_{N \max }$ Maximum Contact Force

IPL Instantaneous Power Losses

LCM Load Contact Model

$L S$ Load Sharing

$O C$ Operating Conditions

$P_{h}$ Medium Hertzian pressure

$R_{a}$ Mean Roughness

$S C R$ Single-contact region

$S D C R$ Second double-contact region

$S R$ Slide-to-Roll ratio $\left(\frac{2\left(u_{1}-u_{2}\right)}{\left(u_{1}+u_{2}\right)}\right)$

$V$ Pitch line velocity

$\eta$ Dynamic Viscosity

$\rho_{c}$ Equivalent Curvature Radius in the pitch point

$\theta$ Rotation angle

$\varphi$ Pressure angle

$b$ Gear Width

$h_{c}$ Central film thickness 


\section{Introduction}

One of the most used mechanical transmissions is the one which transmits the energy by means of gears. This kind of transmission is widespread because of its intrinsic characteristics in the most adverse operating conditions $[34,35]$, being their high efficiency one of the reasons why they are so widely used.

In parallel to the study of gear transmissions, in the current context, fossil fuel is a non-renewable source of energy which is of great interest to reduce its consumption, since it is expensive and polluting. For this reason, the scientific community has focused its efforts on two alternatives to decrease this consumption; Renewable energy sources and reducing the inefficiencies of fossil fuel-consuming systems. Today, the first of these alternatives is in full development and is causing a change in the electric mix of the countries that are installing these technologies. Nevertheless, it has not been imposed yet due to the need for longer operating time, in order to be competitive, and due to the ingrained culture of fossil fuel usage in our society. Regarding the second alternative, the power losses and inefficiencies derived from the energy consumption are inherent to any system, either electrical or mechanical. One of the most used mechanical system by society is the vehicle, whose movement is generated and transmitted through the elements that together comprise what is called powertrain. In line with the reduction of power losses in powertrains, the gear transmissions efficiency, as a crucial part of powertrains, is a compelling field to study $[1,25,31,33,40,43]$. In this regard, there is an industry demand for increasingly efficient transmissions, first, because of the energy reduction and therefore of operating costs, and second, in order to meet the newer environmental requirements [36].

In this proposal, the efficiency due to gear elements is taken into account, because the other elements' efficiency can be neglected in the studied operating conditions $[1,12,40]$. Making this assumption, gear power losses can be distinguished by their load dependency. In turn, those which depend on the load can be classified in sliding and rolling friction and non-load-dependent power losses are conditioned by the fluid in contact with the transmission. In the operating conditions of the study, sliding friction produces the majority of the system power losses (approximately 95\%) [1, 40]. Hence, the assumption of considering sliding friction as the only system dissipative effect is commonly made in the scientific literature [2, 19, 37, 41, 42, 43].

The aim of this assessment is to determine the friction coefficient impact 
on the power losses of spur gears with tip reliefs. In this respect, several researchers have studied the tip relief effects on the dynamic properties of the system $[6,18,22,23,26,27,28]$ and on the tooth resistance $[24,30$, 38], nevertheless, this parameter influence has not been so assessed on the efficiency field, existing just a few studies [5, 8, 29, 43]. Within this context, this proposal strength lies in the use of a Load Contact Model $(L C M)$, which allows for an enhanced calculation of both the friction coefficient $(F C)$ and load sharing, and therefore, allows for obtaining accurate efficiency values $[4,8,12,32]$. As something worth of mention, this $L C M$ takes into account the torque level and profile modification effects on the friction coefficient and load sharing. This $L C M$ has been previously developed by the authors [13, $16,44]$, extended to the modelling of planetary gears [20, 21] and currently used to calculate the efficiency of spur gear transmissions [9, 10]. This $L C M$ allows for including profile modifications, which affect directly the dynamic behaviour and efficiency of the system, as well as opens the possibility of studying manufacturing and assembly errors $[14,15]$ effects on power losses.

As commented, this proposal is mainly focused on the friction coefficient role in the efficiency of this kind of gear transmissions, since the load sharing role was analysed before [10]. This is the reason why two friction coefficient formulations have been implemented. One commonly used in the traditional efficiency calculation procedures, which was developed by Schlenk and used by Niemann, and another advanced formulation based on elastohydrodynamic lubrication fundamentals, which is denominated as 'hybrid formulation'. In this manner, it can be established the differences between the hybrid formulation with respect to the simple Niemann's $F C$ in the efficiency and friction coefficient values. Summarising, this efficiency calculation procedure presents two advantages with respect traditional approaches. An enhanced load sharing which allows for obtaining more accurate results of efficiency than traditional approaches and the use of an advanced friction coefficient formulation, which can reproduce the friction behaviour in different regimes of lubrication and is dependent of the contact force (load sharing) $[4,11,12]$.

In Section 2, the summary of the utilised efficiency procedure is presented. Since this efficiency assessment was carried out to a gear transmission with tip reliefs, the definition of the profile modification model is compulsory and presented in Section 3. Section 4 provides the studied transmission properties and shows the results of the efficiency assessment. Finally, the conclusions are outlined in Section 5. 


\section{Efficiency calculation}

The efficiency calculation methodology was exposed in previous studies [9]. Consequently, only a few details necessary for the work comprehension are described next.

Sliding friction formulation follows the Coulomb's model. This is the reason why power losses are dependent of the friction coefficient $(\mu(\theta))$, sliding velocity factor $\left(\frac{V_{s}(\theta)}{V}\right)$ and load sharing $\left(\frac{F_{N}(\theta)}{F_{N \max }}\right)[9,10]$, where $V$ is the pitch line velocity, $\theta$ the rotation angle and $F_{N \max }$ the maximum normal force. Their multiplication is denominated as Instantaneous Power Loss $(I P L)$ factor (equation 1).

$$
I P L=\frac{\mu(\theta) F_{N}(\theta) V_{s}(\theta)}{F_{N \max } V}
$$

The sliding velocity factor is kinematically determined, thus, the interest lies in the assessment of the other two parameters, which are presented in the next two subsections.

\subsection{Friction coefficient}

In this study, in order to calculate the friction coefficient $(F C)$, two formulations were implemented. The former is a constant average value along the mesh cycle and the latter is an advanced friction coefficient formulation capable to reproduce its behaviour in dry contact, boundary, mixed and fluid film conditions of lubrication.

Niemann's formulation. This friction coefficient is widely used in the scientific literature in order to calculate the system efficiency because it simplifies the procedure $[2,12,19,32,37]$. This formulation, which was developed by Schlenk and generally applied to Niemann's efficiency calculation procedure [19], is dependent of the applied force, the transmission geometry, the transmission speed and the fluid in the conjunction.

$$
\begin{gathered}
\mu_{m}=0.048\left(\frac{\frac{F_{N \max }}{b}}{V_{\Sigma C} \rho_{c}}\right)^{0.2} \eta^{-0.05} R_{a}^{0.25} X_{L} \\
\Rightarrow V_{\Sigma C}=2 V_{t} \sin (\varphi) \quad \text { and } \quad X_{L}=\frac{1}{\left(\frac{F_{N \max }}{b}\right)^{0.0651}}
\end{gathered}
$$


Where $b$ is the gear width, $\rho_{c}$ the equivalent curvature radius in the pitch point, $\eta$ the lubricant dynamic viscosity, $\varphi$ the pressure angle and $R_{a}$ the mean roughness of the profiles in contact.

Hybrid formulation. This formulation is valid in dry contact conditions, boundary, mixed and fluid film lubrication $[4,11]$ and integrates, by a weighting function $\left(f_{\lambda}(\theta)\right)$, a friction coefficient in fluid film lubrication $\left(\mu^{F L}(\theta)\right)$ and a dry contact friction coefficient $\left(\mu^{D C}\right)$, as presented in equation 3 .

$$
\mu^{M L}(\theta)=\mu^{F L}(\theta) f_{\lambda}(\theta)+\mu^{D C}\left(1-f_{\lambda}(\theta)\right)
$$

In this proposal, the considered weighing function was the one developed by Castro et al. (equation 4), which is dependent on the Stribeck parameter $(\lambda(\theta))$ and therefore on the lubrication regime [4].

$$
f_{\lambda}(\theta)=0.82 \lambda(\theta)^{0.28} \Rightarrow \lambda(\theta)=h_{c}(\theta) / R_{a}
$$

Where $h_{c}(\theta)$ is the central film thickness and was obtained by the Dowson and Hamrock formulation for line contacts [17, 25, 39].

With regard to the dry contact friction coefficient, an experimental value were implemented for the considered steel alloy $\left(\mu^{D C}=0.227098\right)[7]$.

Moreover, the formulation used to include the friction coefficient in fluid film lubrication $\left(\mu^{F L}(\theta)\right)$ was developed by $\mathrm{Xu}$ et al. (equation 5$)[45,46]$.

$$
\begin{aligned}
& \mu^{F L}(\theta)=e^{f\left(S R, P_{h}, \eta, R_{a}\right)} P_{h}^{b_{2}}|S R|^{b_{3}} V_{e}^{b_{6}} \eta^{b_{7}} \rho_{e q}^{b_{8}} \\
& \quad \Rightarrow f\left(S R, P_{h}, \eta, R_{a}\right)=b_{1}+b_{4}|S R| P_{h} \log \eta+b_{5} e^{-|S R| P_{h} \log \eta}+b_{9} e^{R_{a}}
\end{aligned}
$$

Where $S R$ is the sliding-to-rolling ratio which is determined by the division of sliding and entraining velocity and $P_{h}$ is the maximum Hertzian contact pressure $(\mathrm{GPa})$ and $b_{j}$ constants are $b_{j}=[-8.916465,1.03303,1.036077$, $-0.354068,2.812084,-0.100601,0.752755,-0.390958,0.620305]$.

The properties of the considered mineral oil (75W90) are the same as in previous studies $[9,10]$.

\subsection{Load sharing}

In order to calculate this parameter, it was used the Load Contact Model previously developed by the authors $[13,16,44]$. This $L C M$ superposes a global and a local model to obtain the gear transmission deflections (Figure 1 ), allowing for considering the torque effect of the system in the deformations 
calculation. Specifically, in order to calculate global deflections, two Finite Elements Models are used to neglect the local distortion obtained from forces applied in one point (point loads), as well as the structural behaviour of the gear. In order to include the distribution of the load in the contact, since the contact is not produced in one point but in an area, the local model deflections are incorporated. This model consists of an analytical formulation developed by Weber-Banashek, which provides the deformations of the tooth depending on the load and material and geometry properties $[9,16]$.

\section{GLOBAL LOCAL TOTAL}

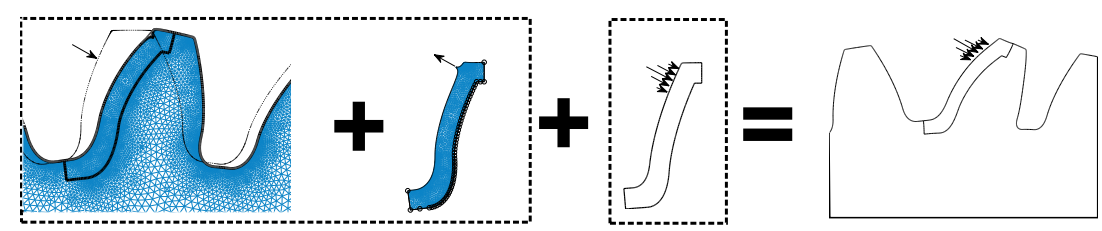

Figure 1: Total deflections by the addition of the local and global deflection models

Once the deflections are calculated, the static equilibrium is reached between the different forces of the system and the external applied torque, for different angular positions (quasi-static analysis). This is an iterative process, which depends on the forces considered (normal contact forces, rolling and sliding friction, windage and churning) and provides, among other results, the $L S$ formulation. In this proposal, the normal contact and the sliding friction forces were taken into account in the torque equilibrium. As a matter of fact, in Figure 2, it can be noticed that there is a $L S$ dispersion in the single contact region when different friction coefficients are implemented.

From the efficiency point of view, this variation can be neglected because it occurs in the pitch point region, where the sliding velocity is close to be null. This is the reason why in the results section (Section 4), only the load sharing corresponding to the hybrid formulation is presented.

\section{Tip relief formulation}

Profile modifications are generally used to improve the transmission dynamic behaviour by softening the transition between the double and the single contact regions. This fact is having an impact on the parameters on which the power losses depend, and therefore, is of great interest to study. 


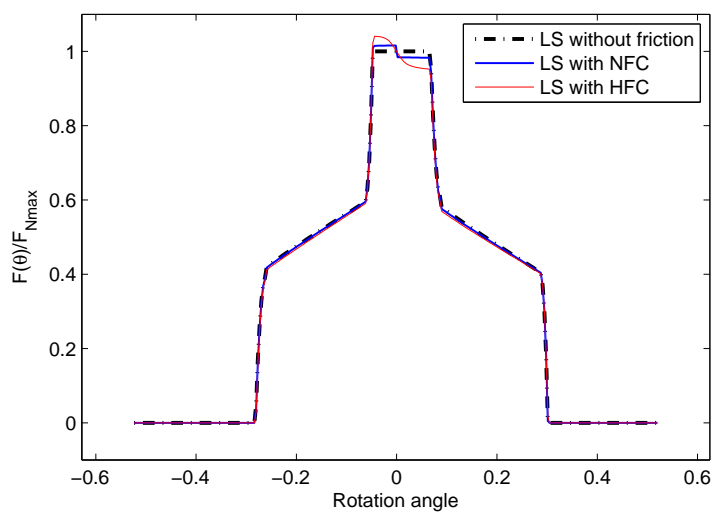

Figure 2: Example of $L S$ without profile modifications (159 Nm and $1500 \mathrm{rpm})$ : without friction, with Niemann's (NFC) and with hybrid (HFC) friction coefficients

The formulation utilised in the $L C M$ to incorporate their behaviour is presented in equation 6 and is illustrated in Figure 3.

$$
e(s)= \begin{cases}0 & s \in\left[0, s_{T_{0}}\right] \\ C_{T}\left(\frac{s-s_{T_{0}}}{\Delta L_{T}}\right)^{n} & s \epsilon\left[s_{T_{0}}, s_{T_{f}}\right]\end{cases}
$$

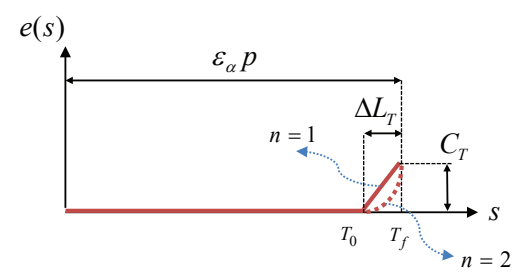

Figure 3: K-chart and nomenclature used to define gear tip reliefs

Where $\varepsilon_{\alpha}$ is the contact ratio, $p$ the circular pitch and $e(s)$ is the profile deviation and represents the gap measured in the line of action that the tip relief produces with respect to the theoretical involute profile. Subscript "T" means that it is a tip relief, which is defined by its magnitude $(C)$ and its length $(\Delta L)$. Although bottom reliefs (" $B$ ") have not been used in the study, the model formulates their behaviour in the same manner. Moreover, these profile modifications could be linear $(n=1)$ or parabolic $(n=2)$, being the former the ones considered in the present work, because in the analysis 
operating conditions, the fact that profile modifications are whether linear or parabolic does not affect the load sharing shape [26].

Furthermore, two kinds of tip reliefs are usually implemented, long and short. The former are commonly used in highly-loaded transmissions, whilst the latter are included in transmissions under low-loaded operating conditions. When long tip reliefs are considered, the theoretical contact ratio becomes lower than the unity, being higher when short tip reliefs are considered [3]. In dynamic regime, a theoretical contact ratio lower than the unity is not advisable, since impacts are expected. Nonetheless, in reality, as the deflections in highly-loaded transmissions are important, a unity value of effective contact ratio can be obtained by choosing the proper long tip relief.

\section{Profile modifications assessment}

The spur gear transmission specimen, on which the efficiency was studied, is the same as in previous works (Figure 4) $[9,10]$.

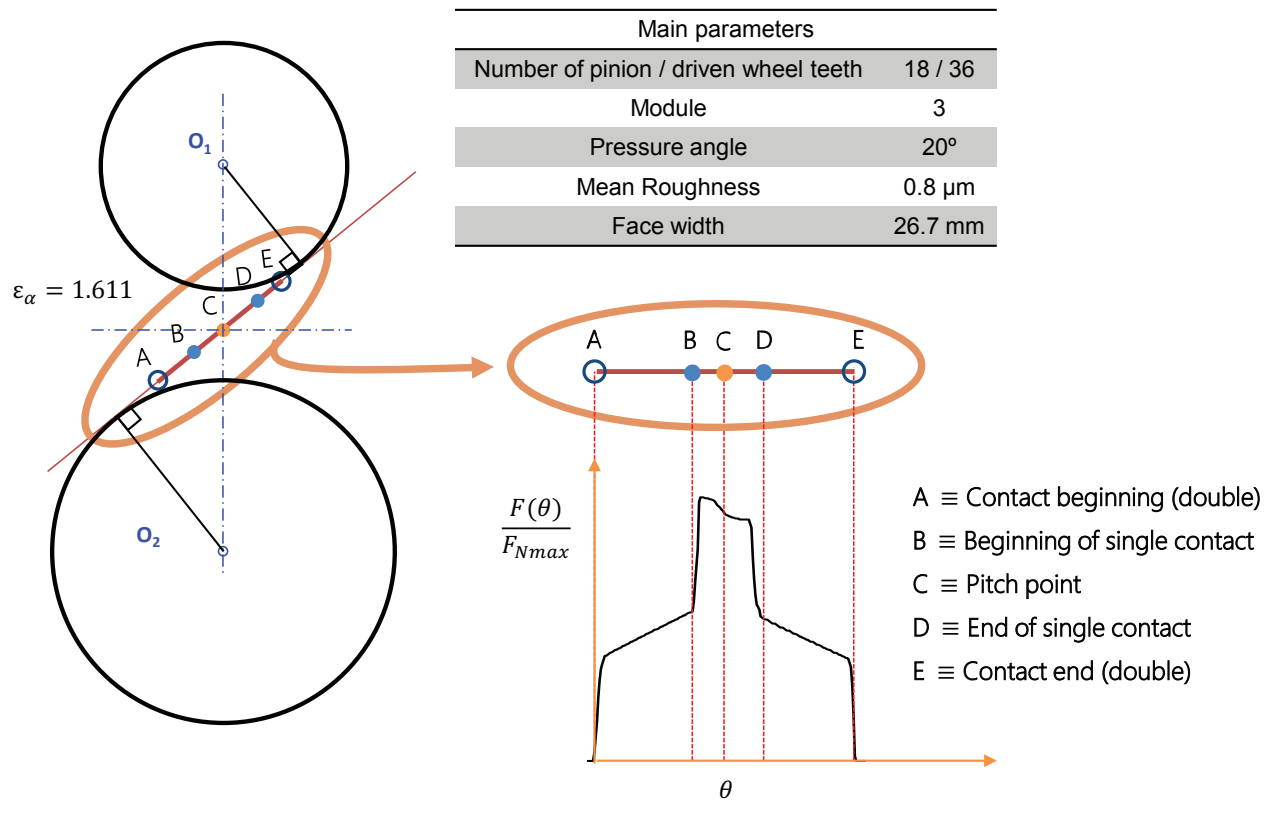

Figure 4: Pinion/driven wheel parameters

This study consists of assessing the impact of the tip relief under low and high torque levels. In Table 1, the tip relief range and the transmission operating conditions are shown. 
Table 1: Tip relief range and transmission operating conditions of the study

\begin{tabular}{cc|cccc}
\hline \multicolumn{2}{c}{ Tip relief $(\mathbf{m m})$} & $\begin{array}{c}\text { Operating } \\
\text { congth }\end{array}$ & $\begin{array}{c}\text { Power } \\
(\mathbf{k W})\end{array}$ & $\begin{array}{c}\text { Torque } \\
(\mathbf{N m})\end{array}$ & $\begin{array}{c}\text { Speed } \\
(\mathbf{r p m})\end{array}$ \\
\hline \multirow{2}{*}{$1 \div 3$} & \multirow{2}{*}{$0.01 \div 0.1$} & OC1 & 25 & 40 & 6000 \\
& & OC2 & 100 & 637 & 1500 \\
\hline
\end{tabular}

In this regard, three case studies of tip reliefs, which are specified in Figure 5, were established to analyse their impact on the efficiency. In the first and second, the efficiency was obtained when the pinion and driven wheel tip reliefs were considered individually, whilst in the third, both gears had the same tip reliefs. The first two case studies allowed for isolating the study of each tip relief kind on the efficiency, whilst the third provided the combination of both previous scenarios.
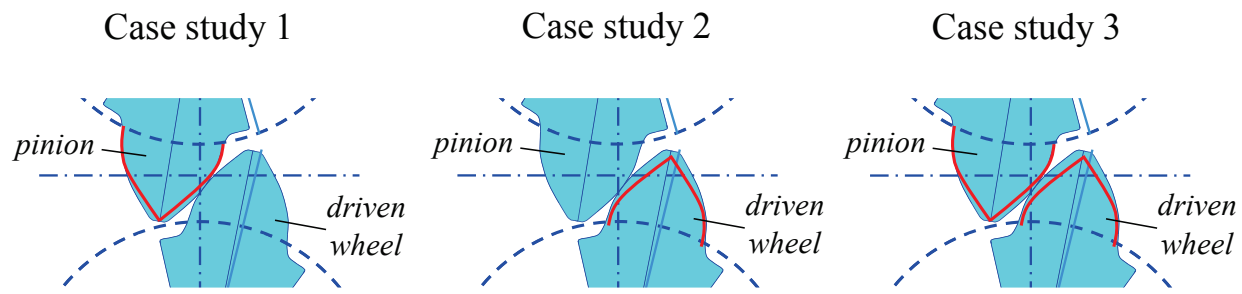

Figure 5: Tip relief case studies

\subsection{Case study 1: Pinion tip reliefs}

The efficiency of the system is presented in Figure 6. In particular, in Figure 6(a), the efficiency was obtained with the implementation of the Niemann's $F C$, whilst in Figure 6(b), the hybrid $F C$ were utilised in the procedure of efficiency calculation.

The efficiency obtained with Niemann's $F C$ is higher than the calculated using hybrid $F C$, regardless of the magnitude or length of the tip relief considered. Furthermore, when Niemann's $F C$ is used, the efficiency is improved with the length of the tip relief in both $O C$ s, whilst, when hybrid $F C$ is considered, the efficiency decreases with the tip relief length in $O C 1$ and is constant in $O C 2$. On the other hand, the magnitude of the tip relief only affects $O C 2$ for both $F C$ formulations, increasing the system efficiency. 


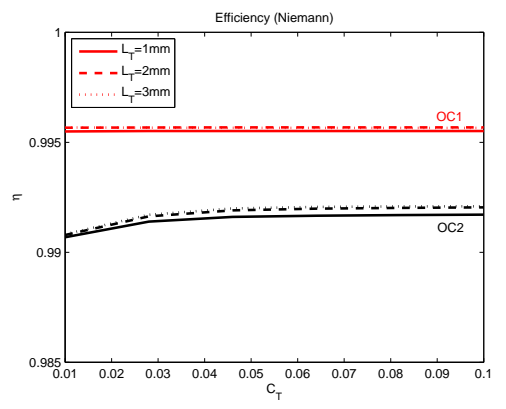

(a) Efficiency with Niemann's FC

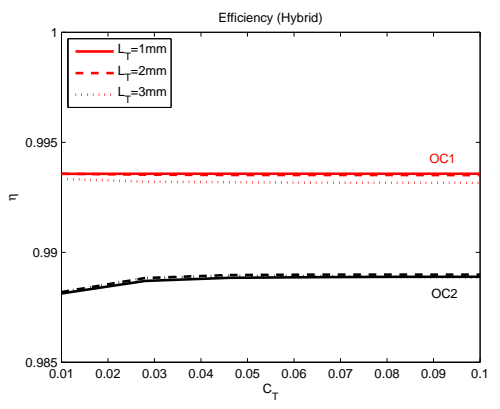

(b) Efficiency with hybrid $F C$

Figure 6: Efficiency for different tip reliefs included in the pinion, under operating conditions 1 (in red) and 2 (in black)

Moreover, as something worth of mention, in the $O C 2$ case, the efficiency is almost constant from a magnitude value equal to $0.05 \mathrm{~mm}$.

In order to explain the efficiency trend, the parameters which affect the efficiency are shown in Figure 7 and Figure 8. Specifically, it is presented the load sharing $(L S)$, the friction coefficient $(F C)$ and the instantaneous power loss factor $(I P L)$ for the smallest and highest magnitudes of tip relief considered.

From both figures, it can be concluded that pinion tip reliefs result in a shortening of the First Double-Contact Region (FDCR) and in a lengthening of the Single-Contact Region $(S C R)$ after the pitch point.

In the smallest magnitude of tip relief case (Figure 7), this fact is solely observed in $O C 1$ (on the left in red colour), whilst in $O C 2$ (on the right in black), it exists a slight load sharing variation in these regions, having no influence on the contact length. These changes in the load sharing affect directly the friction coefficient, which results in variations of the power losses with the tip relief length increment. As a matter of fact, it exists a power loss reduction at the FDCR and a power loss increment in the $S C R$ in the low-torque level case. When Niemann's $F C$ is implemented, the power loss reduction is higher than the increment produced in $S C R$, and therefore, an overall improvement of the efficiency is achieved. Nevertheless, when hybrid $F C$ is included, the contrary occurs, because the $F C$ value is lower at the contact beginning than at the contact end. On the other hand, in the hightorque level case, it only occurs the first effect, a power loss reduction at the contact beginning, obtaining a higher efficiency increment with both $F C$ 

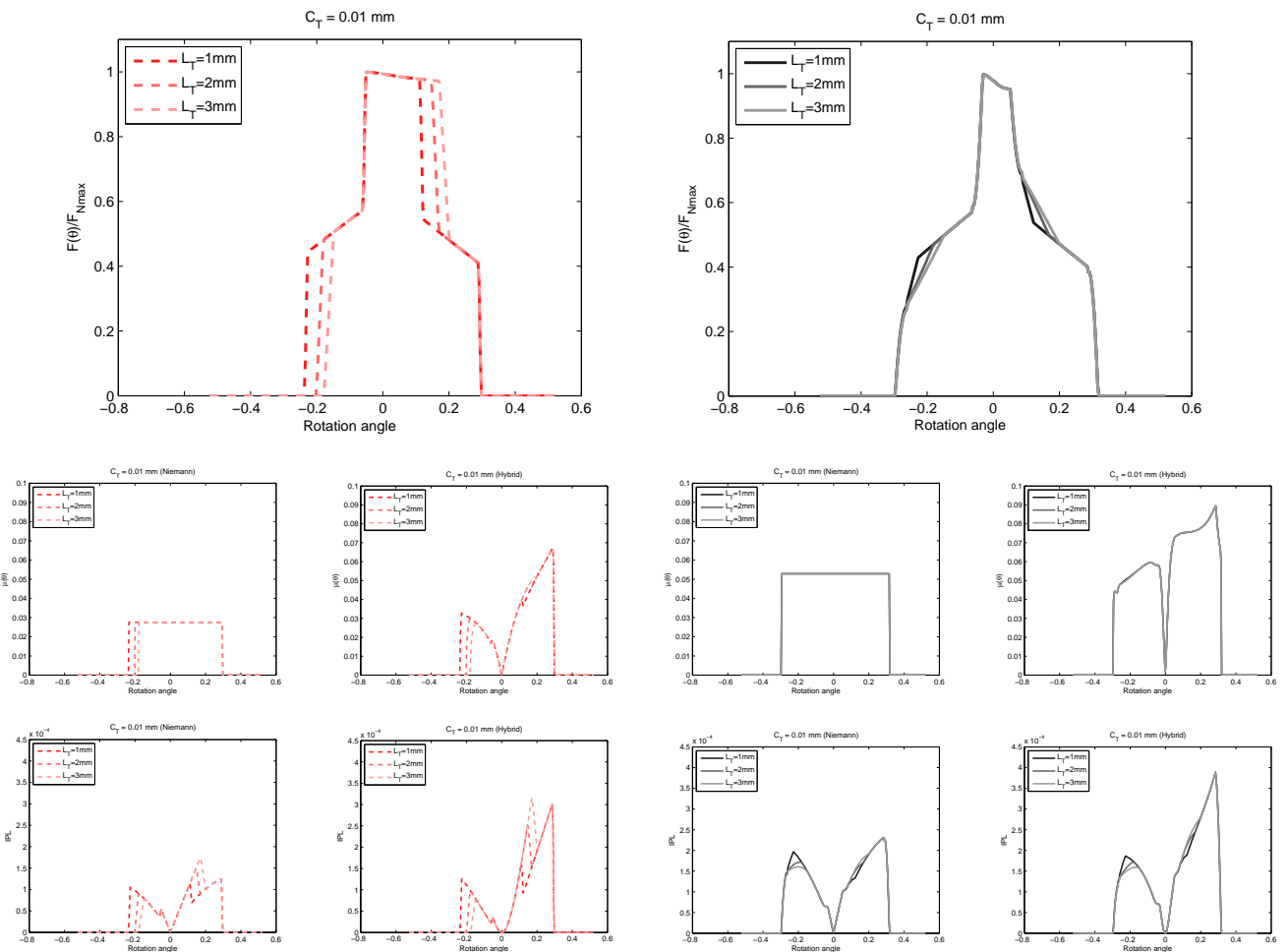

Figure 7: Smallest magnitude case: effect of the modification of tip relief length on the parameters which influence the efficiency

formulations.

In the highest magnitude of tip relief case (Figure 8), there is a contact shortening in both operating conditions as in the smallest magnitude and low-torque level case. As a consequence, the power loss factor follows the explained pattern in that case for both $F C$ formulations.

\subsection{Case study 2: Driven wheel tip reliefs}

In Figure 9, following the same methodology as in the previous case study, the efficiency is presented for some tip reliefs in the driven wheel.

The tip relief length produces an efficiency increment in both operating conditions for both $F C$ formulations, being higher this increment when hybrid $F C$ is implemented. Regarding the magnitude of the tip relief, as in case study 1 , it only affects $O C 2$, following a similar trend.

In order to analyse this tendency, the parameters on which efficiency 

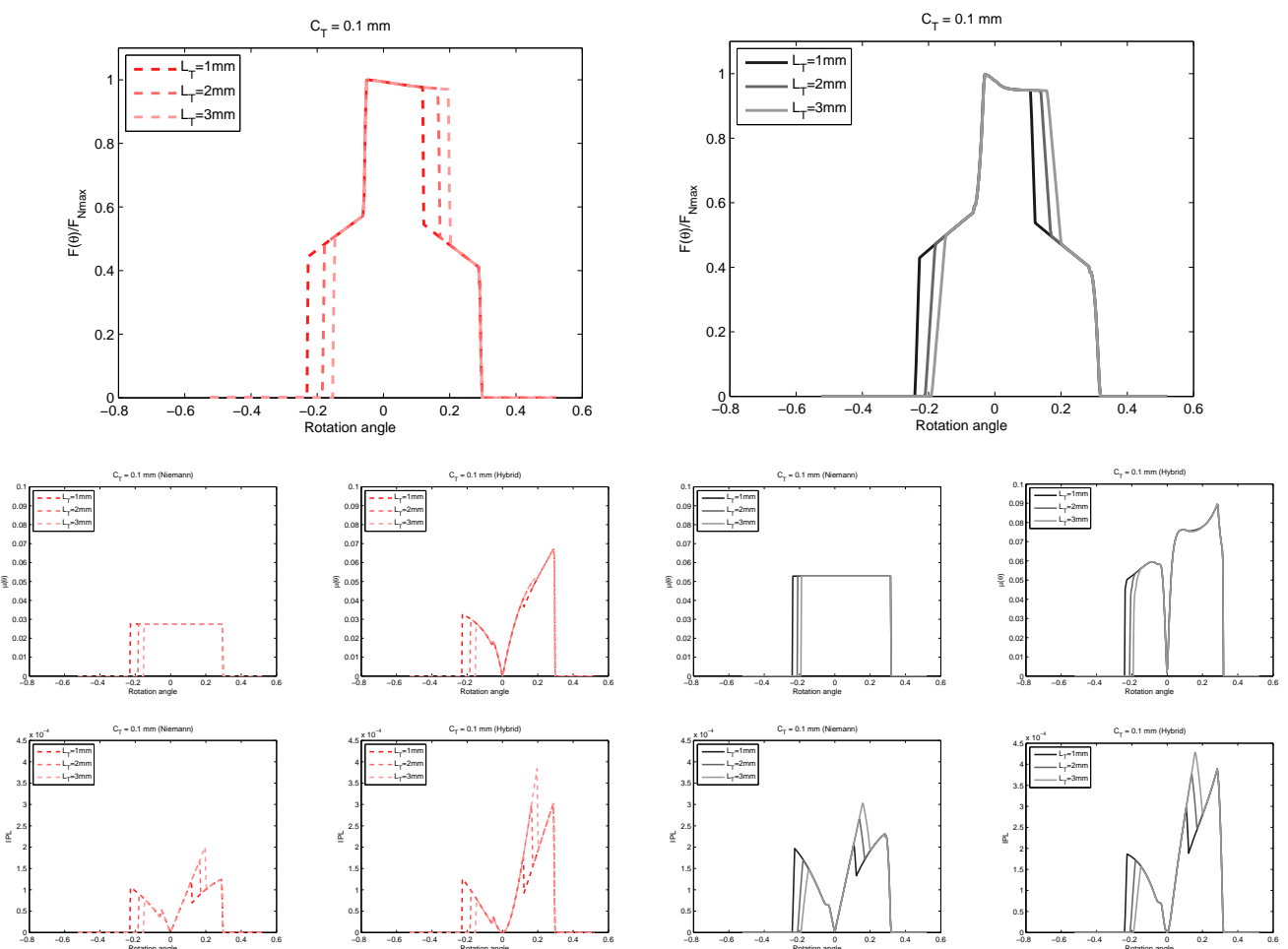

Figure 8: Highest magnitude case: effect of modification of the pinion tip relief length on the parameters which influence the efficiency

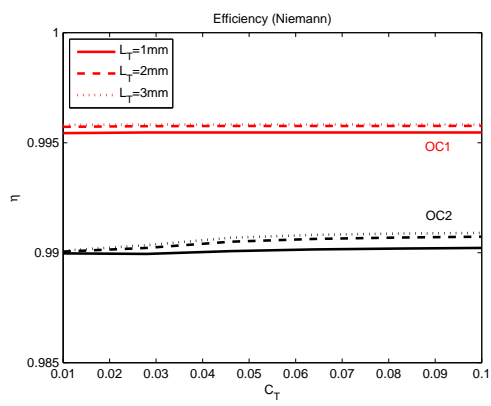

(a) Efficiency with Niemann's FC

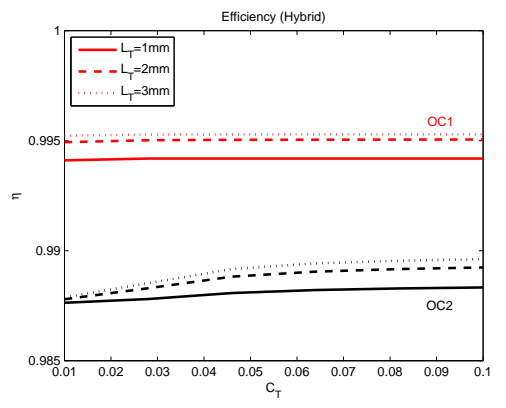

(b) Efficiency with hybrid $F C$

Figure 9: Efficiency for different tip reliefs included in the driven wheel, under operating conditions 1 (in red) and 2 (in black)

depends are presented in Figure 10 and Figure 11, for the smallest and highest 
magnitudes of tip relief.
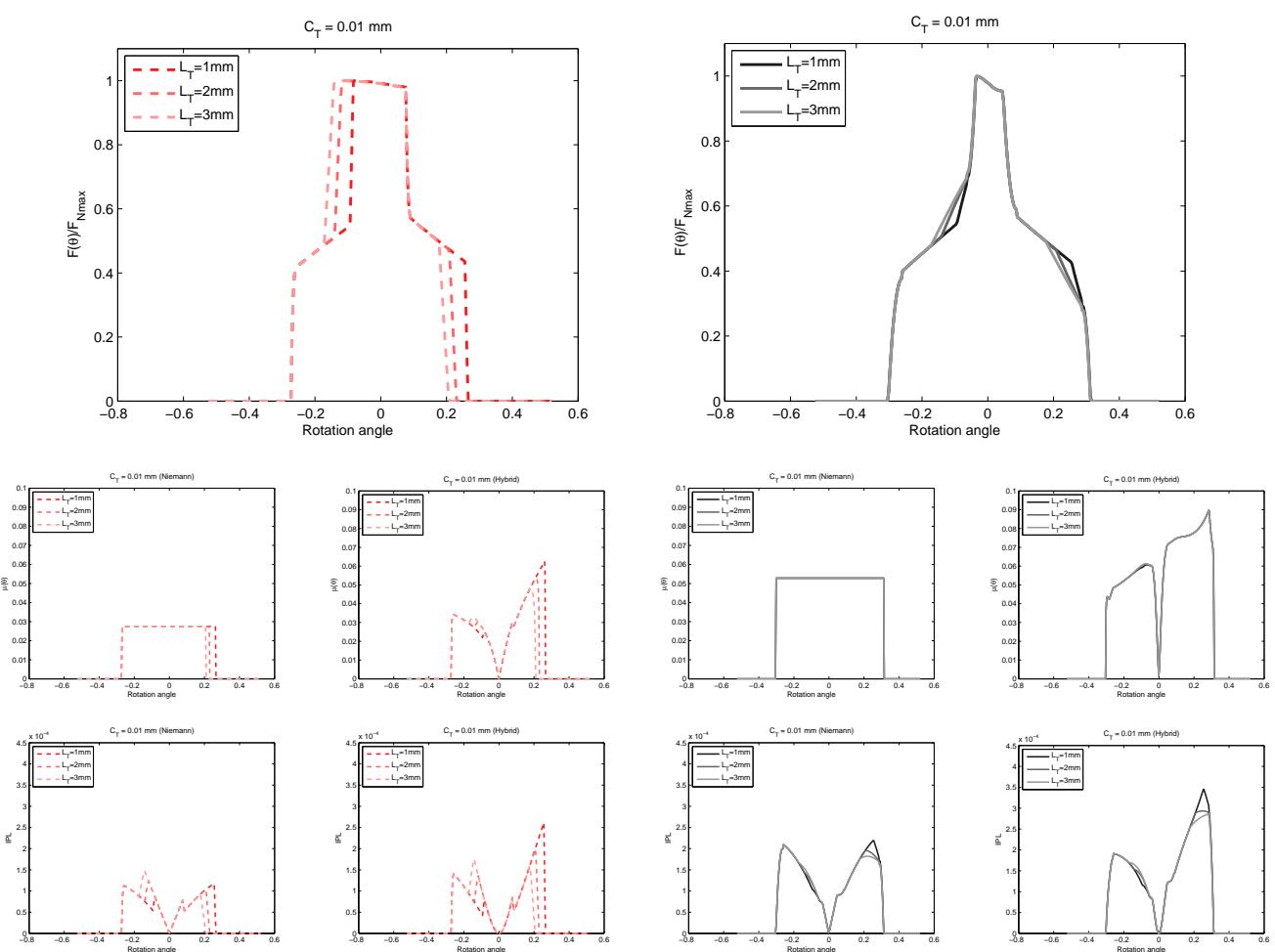

Figure 10: Smallest magnitude case: effect of the modification of tip relief length on the $L S, F C$ and $I P L$ factor

From both figures, it can be inferred that driven wheel tip reliefs turn into a Second Double-Contact Region $(S D C R)$ shortening and into a $S C R$ lengthening before the pitch point.

In the smallest case (Figure 10), the explained effects occur in $O C 1$, however, in $O C 2$, there are slight load sharing variations in these regions, changing the slopes of the $D C R$ s without modifying the contact segment length. Load sharing and friction coefficient are influenced by these facts, resulting in an overall decrement of power losses. As a matter of fact, in $O C 1$, the power loss reduction at the $S D C R$ is higher than the power loss increment at the $S C R$ for both $F C$ formulations, obtaining an efficiency increment. However, in $O C 2$, only the power loss reduction exists for both $F C$ formulations, explaining in this way a higher increment of the efficiency in $O C 2$ than in $O C 1$. 

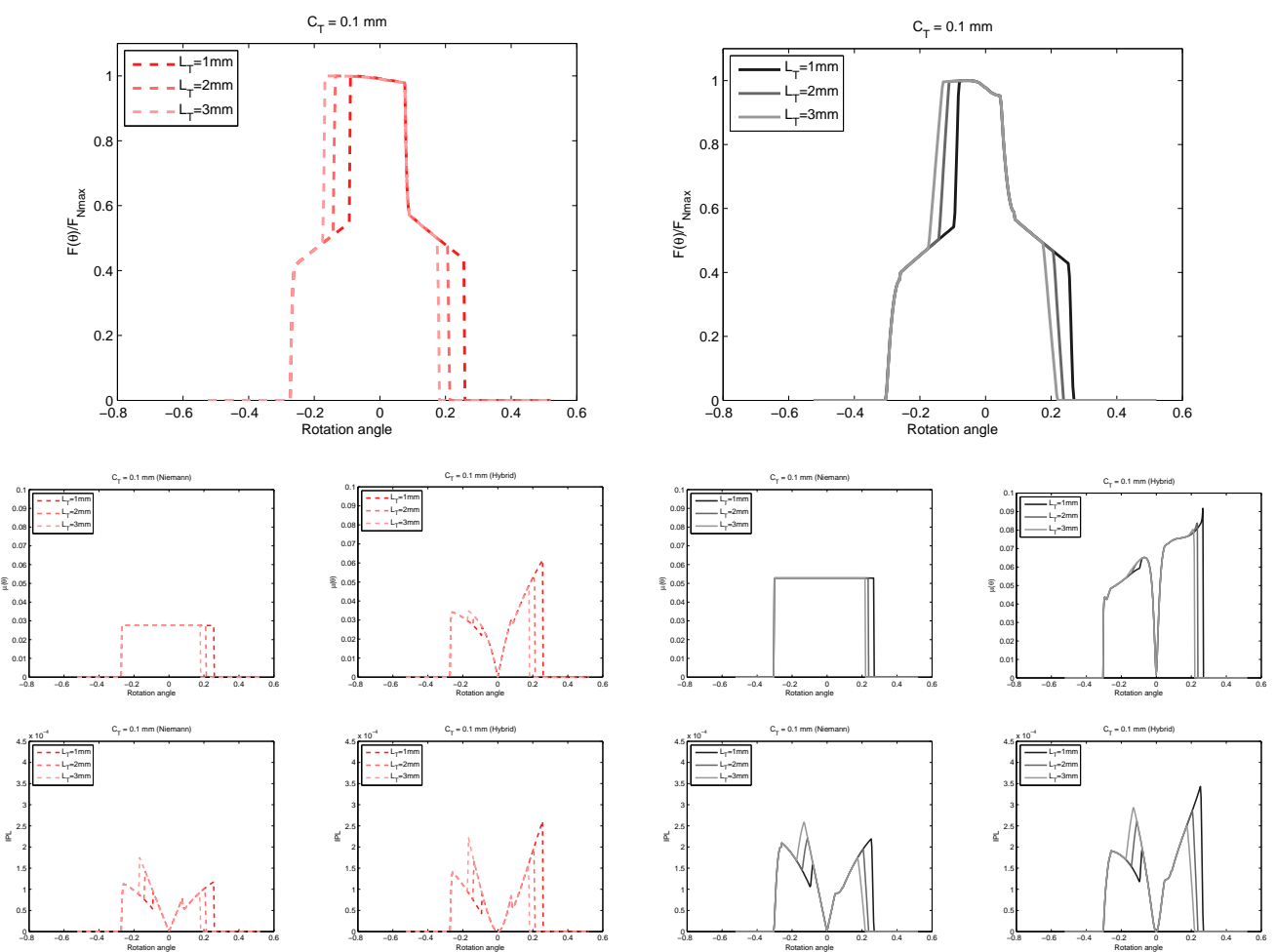

Figure 11: Highest magnitude case: effect of the modification of tip relief length on the $L S, F C$ and $I P L$ factor

In the highest magnitude of tip relief case (Figure 11), the tip relief length increment produces a contact shortening in both $O C$ s. Thus, the power loss decrement in the $S D C R$ is higher than the power loss increment in the $S C R$, resulting in an efficiency improvement for both $F C$ formulations.

\subsection{Case study 3: Same tip reliefs in both wheels}

The efficiency of the system is shown in Figure 12. In this case study, both gears were considered to have the same tip reliefs.

It keeps fulfilling that the efficiency calculated with Niemann's $F C$ is higher than the one corresponding to hybrid $F C$. Not only that, the efficiency is also improved with the length of the tip relief in both operating conditions and the magnitude only affects $O C 2$. Furthermore, if the efficiency among case studies is compared, this efficiency case study is higher than in the other 


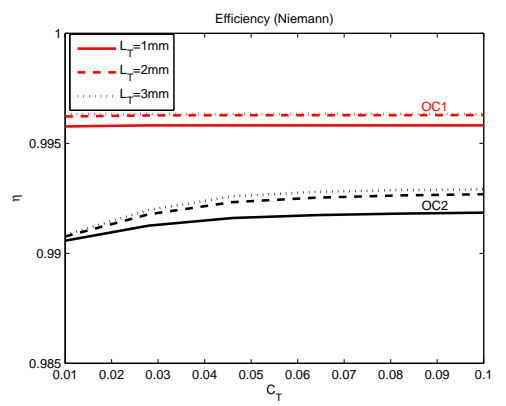

(a) Efficiency with Niemann's FC

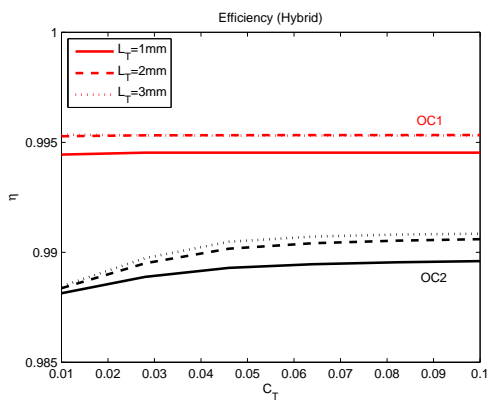

(b) Efficiency with hybrid $F C$

Figure 12: Efficiency for different tip reliefs included in both wheels, under operating conditions 1 (in red) and 2 (in black)

two cases, establishing that including tip reliefs in both wheels is better than in only one from the efficiency point of view.

In Figure 13 and Figure 14, the $L S, F C$ and $I P L$ factor are shown for the smallest and highest magnitudes of tip relief, respectively.

The superposition of the effects of the previous case studies occurred, producing a shortening of both $D C R \mathrm{~s}$ and a $S C R$ lengthening, turning into a higher reduction of the contact segment than in previous case studies.

In the smallest case (Figure 13), these facts only occurs in $O C 1$, since in $O C 2$, there is no contact length modification but load sharing variations in the slopes of the $D C R \mathrm{~s}$. These effects have a major influence on the power losses. Specifically, in $O C 1$, the power loss decrement is higher than the power loss increment in the $S C R$ for both $F C$ formulations. Nevertheless, in $O C 2$, there is no power loss increment in $S C R \mathrm{~s}$, hence, only a power loss reduction exists in the $D C R \mathrm{~s}$, resulting in an efficiency improvement higher than in $O C 1$.

In the highest magnitude of tip relief case (Figure 14), the contact shortening is appreciated in the two $O C$ s and for both $F C$ formulations. The same trend as in the smallest magnitude case and low-torque is observed, turning into an overall power loss reduction with the increment of the tip relief length.

\section{Conclusions}

The friction coefficient effect on spur gear efficiency with tip reliefs was assessed in the present study. For this purpose, two friction coefficient for- 

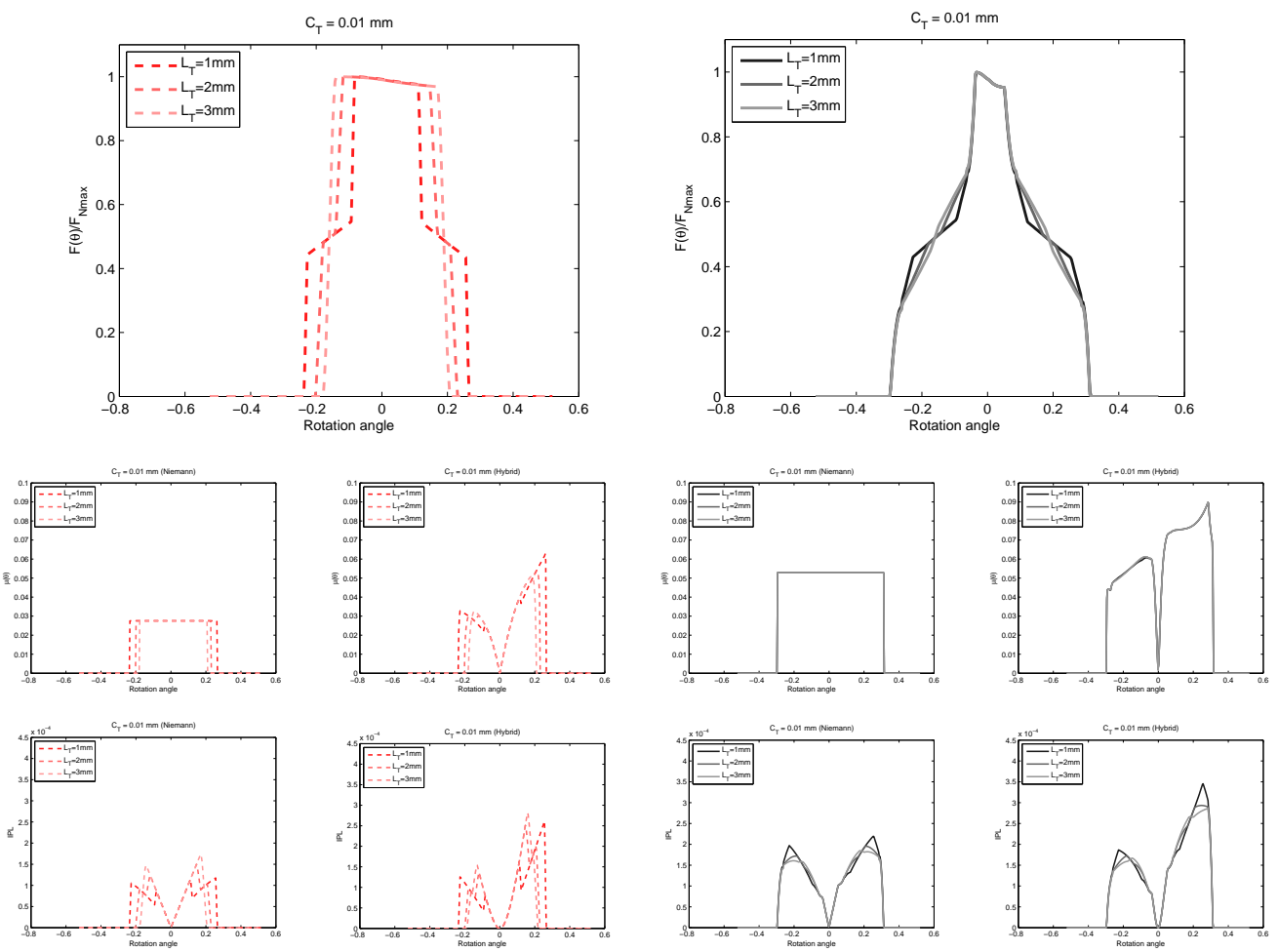

Figure 13: Effect of the tip relief length variation, in the minimum magnitude case, on $L S, F C$ and $I P L$ factor

mulations were implemented. One used in traditional efficiency calculation approaches, which was developed by Niemann's and is constant along the mesh cycle, and an advanced formulation derived from elastohydrodynamic lubrication fundamentals denominated as hybrid formulation. The results obtained implementing both formulations allows to establish the advantages of using each of them and the dissimilarities in efficiency and friction coefficient values.

From this assessment, it was appreciated that the efficiency calculated with hybrid $F C$ was lower than the one obtained with Niemann's $F C$, regardless of where the tip reliefs were included. Comparing among the case studies, the highest efficiency was obtained when tip reliefs were considered in both gears, whilst the lowest efficiency corresponded to the driven wheel tip reliefs in Niemann's $F C$ case and to the pinion tip reliefs in hybrid $F C$ case. Thus, the choice of friction coefficient formulation clearly influences 

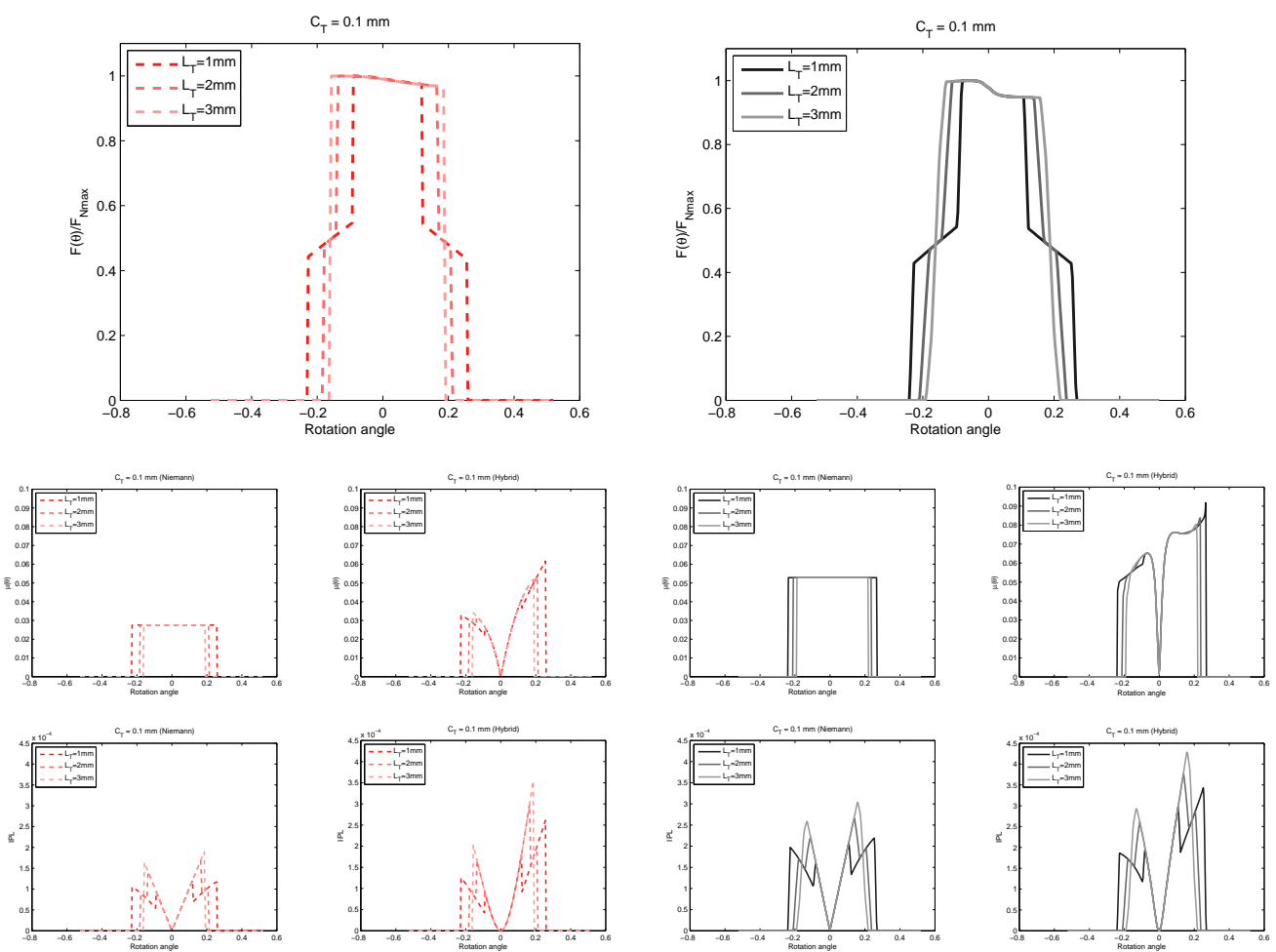

Figure 14: Effect of the tip relief length variation, in the maximum magnitude case, on $L S, F C$ and $I P L$ factor

the efficiency results in gear transmissions with tip reliefs.

Furthermore, tip reliefs provoke an effective contact ratio reduction, which generally turns into an efficiency increment. The location of this effective contact length decrement depends on where the tip reliefs are considered, as is known. Pinion tip reliefs turn into a diminution of the first doublecontact region, driven wheel tip reliefs resulted in a reduction of the second double-contact, whilst tip reliefs in both gears produced the superposition of the commented effects. These facts affected directly the load sharing and friction coefficient, and therefore, the system power losses. Since hybrid FC highest value is located at the contact end, when tip reliefs were included in the pinion, the efficiency remained constant or decreased, nevertheless, when the tip reliefs were considered in the driven wheel, the efficiency increased and, as a matter of fact, this efficiency increment was higher than the one obtained with Niemann's FC, producing discrepancies between formulations. 
Acknowledgments The authors would like to acknowledge Project DPI 2013-44860 funded by the Spanish Ministry of Science and Technology.

\section{References}

[1] N. E. Anderson and S. H. Loewenthal. Spur-gear-system efficiency at part and full load. NASA Technical Paper, (1622), 1980.

[2] S. Baglioni, F. Cianetti, and L. Landi. Influence of the addendum modification on spur gear efficiency. Mechanism and Machine Theory, 49:216$233,2012$.

[3] G. Bonori, M. Barbieri, and F. Pellicano. Optimum profile modifications of spur gears by means of genetic algorithms. Journal of Sound and Vibration, 313(3-5):603-616, 2008.

[4] J. Castro and J. Seabra. Coefficient of friction in mixed film lubrication: Gears versus twin-discs. Proceedings of the Institution of Mechanical Engineers, Part J: Journal of Engineering Tribology, 221(3):399-411, 2007.

[5] L. Chang, Y.-R. Jeng, and P.-Y. Huang. Modeling and analysis of the meshing losses of involute spur gears in high-speed and high-load conditions. Journal of Tribology, 135(1), 2013.

[6] Z. Chen and Y. Shao. Mesh stiffness calculation of a spur gear pair with tooth profile modification and tooth root crack. Mechanism and Machine Theory, 62:63 - 74, 2013.

[7] W. Chong and M. De La Cruz. Elastoplastic contact of rough surfaces: A line contact model for boundary regime of lubrication. Meccanica, 49(5):1177-1191, 2014.

[8] Y. Diab, F. Ville, and P. Velex. Prediction of power losses due to tooth friction in gears. Tribology Transactions, 49(2):266-276, 2006.

[9] A. Diez-Ibarbia, A.F. del Rincon, M. Iglesias, A. de Juan, P. Garcia, and F. Viadero. Efficiency analysis of spur gears with a shifting profile. Meccanica, 51(3):707-723, 2016. 
[10] A. Diez-Ibarbia, A. Fernandez-del Rincon, A. de Juan, M. Iglesias, P. Garcia, and F. Viadero. Frictional power losses on spur gears with tip reliefs. the load sharing role. Mechanism and Machine Theory, 112:240$254,2017$.

[11] Z. Feng, S. Wang, T.C. Lim, and T. Peng. Enhanced friction model for high-speed right-angle gear dynamics. Journal of Mechanical Science and Technology, 25(11):2741-2753, 2011.

[12] C. Fernandes, P. Marques, R. Martins, and J. Seabra. Gearbox power loss. part ii: Friction losses in gears. Tribology International, 88:309 316, 2015.

[13] A. Fernandez-del Rincon, P. Garcia, A. Diez-Ibarbia, A. de Juan, M. Iglesias, and F. Viadero. Enhanced model of gear transmission dynamics for condition monitoring applications: Effects of torque, friction and bearing clearance. Mechanical Systems and Signal Processing, 85:445-467, 2017.

[14] A. Fernández-Del-Rincón, M. Iglesias, A. De-Juan, A. Diez-Ibarbia, P. García, and F. Viadero. Gear transmission dynamics: Effects of index and run out errors. Applied Acoustics, 108:63-83, 2016.

[15] A. Fernández del Rincón, M. Iglesias, A. De-Juan, P. García, R. Sancibrián, and F. Viadero. Gear transmission dynamic: Effects of tooth profile deviations and support flexibility. Applied Acoustics, 77(0):138149, 32014.

[16] A. Fernández Del Rincón, F. Viadero, M. Iglesias, P. García, A. DeJuan, and R. Sancibrian. A model for the study of meshing stiffness in spur gear transmissions. Mechanism and Machine Theory, 61:30-58, 2013.

[17] B. J. Hamrock, S.R. Schmid, and B.O. Jacobson. Fundamentals of Fluid Film Lubrication. New York: Marcel Dekker, second edition edition, 2004.

[18] S. He, R. Gunda, and R. Singh. Effect of sliding friction on the dynamics of spur gear pair with realistic time-varying stiffness. Journal of Sound and Vibration, 301(3-5):927 - 949, 2007. 
[19] B. R Höhn. Improvements on noise reduction and efficiency of gears. Meccanica, 45(3):425-437, 2010.

[20] M. Iglesias, A. Fernandez del Rincon, A. de Juan, A. Diez-Ibarbia, P. Garcia, and F. Viadero. Advanced model for the calculation of meshing forces in spur gear planetary transmissions. Meccanica, 50(7):18691894, 2015.

[21] M. Iglesias, A. Fernandez del Rincon, A. de Juan, P. Garcia, A. DiezIbarbia, and F. Viadero. Planetary transmission load sharing: Manufacturing errors and system configuration study. Mechanism and Machine Theory, 111:21-38, 2017.

[22] A. Kahraman and G.W. Blankenship. Effect of involute tip relief on dynamic response of spur gear pairs. Journal of Mechanical Design, Transactions of the ASME, 121(2):313-315, 1999.

[23] S. Li. Effects of machining errors, assembly errors and tooth modifications on loading capacity, load-sharing ratio and transmission error of a pair of spur gears. Mechanism and Machine Theory, 42(6):698 - 726, 2007.

[24] S. Li. Finite element analyses for contact strength and bending strength of a pair of spur gears with machining errors, assembly errors and tooth modifications. Mechanism and Machine Theory, 42(1):88 - 114, 2007.

[25] S. Li and A. Kahraman. Prediction of spur gear mechanical power losses using a transient elastohydrodynamic lubrication model. Tribology Transactions, 53(4):554-563, 2010.

[26] H.S. Lin, F.B. Oswald, and D.P. Townsend. Dynamic loading of spur gears with linear or parabolic tooth profile modifications. Mechanism and Machine Theory, 29(8):1115-1129, 1994.

[27] G. Liu and R.G. Parker. Dynamic modeling and analysis of tooth profile modification for multimesh gear vibration. Journal of Mechanical Design, Transactions of the ASME, 130(12):1214021-12140213, 2008.

[28] H. Ma, J. Zeng, R. Feng, X. Pang, and B. Wen. An improved analytical method for mesh stiffness calculation of spur gears with tip relief. Mechanism and Machine Theory, 98:64 - 80, 2016. 
[29] L. Magalhes, R. Martins, C. Locateli, and J. Seabra. Influence of tooth profile and oil formulation on gear power loss. Tribology International, 43(10):1861-1871, 2010.

[30] K. Marković and Ž. Vrcan. Influence of tip relief profile modification on involute spur gear stress. Transactions of Famena, 40(2):59-70, 2016.

[31] P. Marques, R. Martins, and J. Seabra. Power loss and load distribution models including frictional effects for spur and helical gears. Mechanism and Machine Theory, 96:1-25, 2016.

[32] K. Michaelis, B. R Höhn, and M. Hinterstoißer. Influence factors on gearbox power loss. Industrial Lubrication and Tribology, 63(1):46-55, 2011.

[33] M. Mohammadpour, S. Theodossiades, H. Rahnejat, and P. Kell. Transmission efficiency and noise, vibration and harshness refinement of differential hypoid gear pairs. Proceedings of the Institution of Mechanical Engineers, Part K: Journal of Multi-body Dynamics, 228(1):19-33, 2014.

[34] E. Mucchi, G. Dalpiaz, and A. Fernandez del Rincon. Elasto-dynamic analysis of a gear pump-part iv: Improvement in the pressure distribution modelling. Mechanical Systems and Signal Processing, 50:193$213,2015$.

[35] E. Mucchi, G. Dalpiaz, and A. F. Del Rincon. Elastodynamic analysis of a gear pump. part i: Pressure distribution and gear eccentricity. Mechanical Systems and Signal Processing, 24(7):2160-2179, 2010.

[36] Official Journal of the European Communities. Commission regulation (EC) No 692/2008 of 18 July 2008 implementing and amending regulation (EC) No 715/2007 of the european parliament and of the council on type-approval of motor vehicles with respect to emissions from light passenger and commercial vehicles (euro 5 and euro 6) and on access to vehicle repair and maintenance information (1). Official Journal of the European Communities, 2008.

[37] H. Ohlendorf. Verlustleistung und erwärmung von stirnrädern, 1958.

[38] D. Palmer and M. Fish. Evaluation of methods for calculating effects of tip relief on transmission error, noise and stress in loaded spur gears. 
American Gear Manufacturers Association Fall Technical Meeting 2010, pages 112-126, 2010.

[39] L. Paouris, S. Theodossiades, M. De La Cruz, H. Rahnejat, A. Kidson, G. Hunt, and W. Barton. Lubrication analysis and sub-surface stress field of an automotive differential hypoid gear pair under dynamic loading. Proceedings of the Institution of Mechanical Engineers, Part C: Journal of Mechanical Engineering Science, 230(7-8):1183-1197, 2015.

[40] T. T. Petry-Johnson, A. Kahraman, N. E. Anderson, and D. R. Chase. An experimental investigation of spur gear efficiency. Journal of $\mathrm{Me}$ chanical Design, Transactions of the ASME, 130(6):0626011-06260110, 2008.

[41] M. Pleguezuelos, J. I. Pedrero, and M. B. Sánchez. Analytical expressions of the efficiency of standard and high contact ratio involute spur gears. Mathematical Problems in Engineering, 2013, 2013.

[42] M.B. Sánchez, M. Pleguezuelos, and J.I. Pedrero. Approximate equations for the meshing stiffness and the load sharing ratio of spur gears including hertzian effects. Mechanism and Machine Theory, 109:231$249,2017$.

[43] P. Velex and F. Ville. An analytical approach to tooth friction losses in spur and helical gears-influence of profile modifications. Journal of Mechanical Design, Transactions of the ASME, 131(10):1010081-10100810, 2009.

[44] F. Viadero, A. Fernandez Del Rincon, R. Sancibrian, P. Garcia Fernandez, and A. De Juan. A model of spur gears supported by ball bearings. In WIT Transactions on Modelling and Simulation, volume 46, pages 711-722, 2007.

[45] H. Xu. Development of a generalized mechanical efficiency prediction methodology for gear pairs, 2005.

[46] H. Xu. A novel formula for instantaneous coefficients of sliding friction in gearing. SAE Technical Papers, 2007. 